\title{
Probabilistic assessment of precipitation-triggered landslides: the role of vegetation
}

\author{
Estefanía Muñoz ${ }^{1,2, a}$, Andrés Ochoa ${ }^{1}$ and Manoel Cordão-Neto ${ }^{2}$ \\ ${ }^{1}$ Departamento de Geociencias y Medio Ambiente, Universidad Nacional de Colombia, Colombia \\ ${ }^{2}$ Departamento de Engenharia Civil e Ambiental, Universidade de Brasília, Brazil.
}

\begin{abstract}
Landslides triggered by rainfall are one of the most common causes of disaster in tropical regions, characterized by having deep weathering soil profiles, steep slopes and high-intensity storms. The increasing number of landslides during wet season evidences the close relationship between hydro-climatic conditions as a triggering factor for the occurrence of landslides. In addition, the type of vegetation covering the slope affects the soil shear strength by the roots reinforcement, plants weight and changes in soil moisture due to transpiration and interception. This paper proposes a probabilistic methodology to study the slope stability on the long-term, considering different hydro-climatic conditions and the effect of vegetation cover in the soil moisture. The ecohydrological model developed by Rodríguez-Iturbe et al. [1] was used to determine the boundary conditions of the problem. To generate the pore pressure field, the flow equation was solved using the Finite Element Method and Finite Differences Method. Finally, the Limit Equilibrium Method was used to find the Factor of Safety. The stability of a hypothetical slope under certain hydro-climatic conditions and two types of vegetation was evaluated. The analysis showed that it is more likely that a grass-covered slope slides than a tree-covered slope, and that the average FS of the slope during wet and dry season is very similar, but the FS dispersion is higher when the probability and intensity of rainfall events increases.
\end{abstract}

\section{INTRODUCTION}

Landslides are closely linked to water content on surface soil layer, which depends mostly on the amount of water precipitated. However, there are many other variables (with nonlinear relationships) that make it impossible to derive a general relation between rainfall and the soil response. There are many approaches in the literature to relate cumulative rainfall and landslides, diverging in the quantity of days to be considered (e.g. [2-9]). The surface soil layers behave as dynamic systems that interact with the atmosphere and the deeper layers, making it necessary to consider the climate-soilvegetation system, to understand the landslide problem.

The climate-soil-vegetation system is influenced by the different relations of dependency and feedback of physical processes on each subsystem. The soil water content is the result of the interaction of processes presented on atmosphere, soil and vegetation [10]. The interactions of the subsystems critically depend on the scales at which the phenomenon is studied, ecophysiological features of vegetation, pedology and climate regime [11].

Climate is an important factor, not only on diffusive processes of evaporation, but on the availability of water

a Corresponding author: emunozh@unal.edu.co for vegetation [11]. Texture, mineralogical composition and arrangement of particles determine water content that the soil is allowed to store [12]. Moreover, vegetation controls energy and water flows, dividing precipitation on interception, runoff, evaporation, transpiration and stored water in the soil, and the energy on sensible and latent heat. After evaporation, transpiration of plants is the most important phenomenon on energy transfer on surface processes [13].

A probabilistic methodology was proposed in this paper to evaluate the slope stability on the long-term, considering the hydro-climatic conditions and the effect of vegetation cover in soil moisture. A modification of the ecohydrological model proposed by Rodríguez-Iturbe et al. [1] and Laio et al.[14] was used to determine boundary conditions of the problem. In order to obtain pore pressure field, the flow equation was solved by the Finite Element Method (FEM) and the Finite Difference Method (FDM). And the Limit Equilibrium Method (FEM) was used to find the Factor of Safety (FS). In addition, the stability of the hypothetical slope, proposed by Otálvaro \& Cordão-Neto [15], covered by two types of vegetation during wet and dry periods was evaluated. 


\section{CLIMATE-SOIL-VEGETATION MODEL}

Figure 1 represents the dynamics of soil water content from the mass balance on plant rooting depth, described by

$$
n Z_{r} \frac{d S_{r}(t)}{d t}=\Phi\left[S_{r}(t), t\right]-\chi\left[S_{r}(t)\right]
$$

where, $n$ is porosity, $Z_{r}$ rooting depth, $S_{r}$ soil degree of saturation, $\Phi$ infiltration rate and $\chi$ water losses.

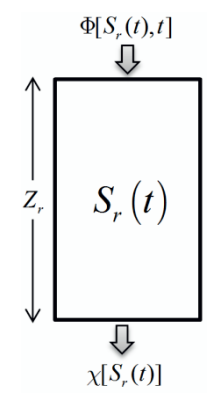

Figure 1. Conceptual model of the soil water content.

On the model initially proposed by Rodríguez-Iturbe et al. [1] and modified by Laio et al.[14], the processes describing the interaction climate-soil-vegetation evolve over time, under the influence of a variable climate.

Infiltration is the stochastic component of the balance and is described by

$$
\Phi\left[S_{r}(t), t\right]=R(t)-I(t)-\varphi\left[S_{r}(t), t\right]
$$

where, $R$ is rainfall rate, $I$ is the amount of rainfall lost through canopy interception and $\varphi$ is the rate of surface runoff generation. Soil water losses are given by

$$
\chi\left[S_{r}(t)\right]=E T\left[S_{r}(t)\right]+L\left[S_{r}(t)\right]
$$

where, $E T$ y $L$ are evapotranspiration and percolation rates respectively, and they depend on water content stored in the soil.

\subsection{Rainfall and interception}

Daily precipitation was modeled as a Rectangular Pulses Poisson Model (RPPM) with arrival rate $\lambda[16]$.

The distribution of times $\Gamma$ between precipitation events is exponential with mean $\lambda^{-1}$, i.e.

$$
f_{\Gamma}(\Gamma)=\lambda e^{-\lambda \Gamma} \text { for } \Gamma \geq 0
$$

The depth of rainfall events was assumed to be an independent random variable $h_{R}$, described by an exponential Probability Density Function (pdf)

$$
f_{H_{R}}\left(h_{R}\right)=\frac{1}{\alpha} e^{-\frac{1}{\alpha} h_{R}}, h_{R} \geq 0
$$

where, $\alpha$ is the mean depth of rainfall events, estimated as the daily mean of days when precipitation occurs.

The mechanisms of interception by vegetation are quite complicated to model, since they depend, among others, on density and architecture of vegetation, besides rainfall intensity and duration. To simplify the model, a threshold $\Delta$ was defined, below which water reaches the ground. When the interception is evaluated, rainfall process is transformed into a new Poisson process, where the frequency of rainfall events $\lambda^{\prime}$ is

$$
\lambda^{\prime}=\lambda \int_{\Delta}^{\infty} f_{H_{R}}\left(h_{R}\right) d h_{R}=\lambda e^{-\frac{\Delta}{\alpha}}
$$

With the amount of water intercepted by plants leaves, it is possible to calculate the effective precipitation $R_{e}$, defined as the amount of water that reaches the soil surface, that is to say, total precipitation minus interception.

\subsection{Infiltration and runoff}

It was assumed that surface runoff starts when soil hydraulic gradient equals zero, and that infiltration has a rate related to soil hydraulic conductivity $k_{w}$.

The values of $k_{w}$ where obtained as a function of soil degree of saturation for each time and saturated hydraulic conductivity coefficient $k_{s}$, following the expression based on the potential law proposed by Campell [17]

$$
k_{w}\left(S_{r}\right)=k_{s} S_{r}^{d}
$$

where, $d=2 b+3$, and $b$ is a soil empirical exponent.

\subsection{Evapotranspiration}

Plants transpiration and soil evaporation are governed by different mechanisms, however, were modeled together, as shown on Figure 2.

Evapotranspiration $E T$ was modeled as a function of soil water content. When soil saturation is higher than the field capacity $S_{f c}$, the evapotranspiration rate is maximum and equal to $E_{\max }$. When the degree of saturation is lower than the degree of saturation of the temporary or incipient wilting point $S^{*}$, transpiration of plants is lowered by the stoma closing to avoid inner water loss. Transpiration rate continues decreasing until the moisture reaches permanent wilting point $S_{w}$. At this point, suction is so high that damages plant tissues, resulting on an irreversible wilting point, making it impossible for the plant to recover its turgidness [18]. For water content lower than $S_{w}$, there is only evaporation with a rate equal to $E_{w}$. Finally, for moistures below hygroscopic $S_{h}$, water cannot be naturally removed. 


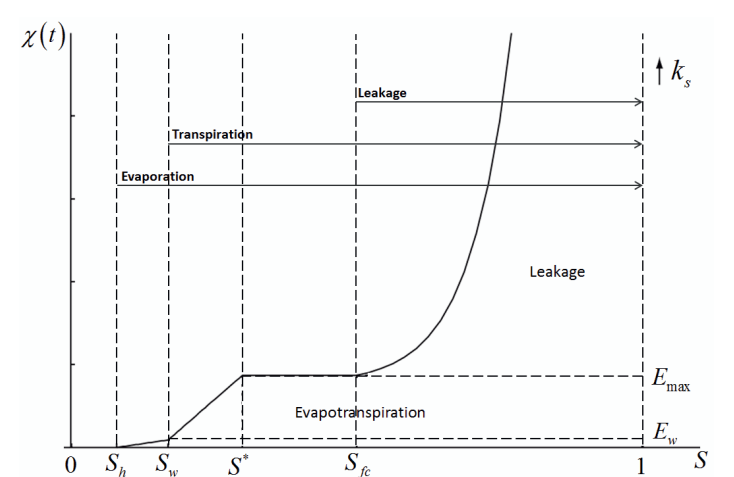

Figure 2. Soil water losses as a function of degree of saturation. Modified from Rodriguez-Iturbe and Porporato [12].

It was assumed that losses by leakage or deep infiltration $L$ start when water content reaches a value higher than $S_{f c}$. The maximum leakage rate equals $k_{s}$, and lowers rapidly when soil starts to dry, following the relation [14]

$$
L\left(\mathrm{~S}_{\mathrm{r}}\right)=\frac{k_{s}}{e^{\beta\left(1-\mathrm{S}_{\mathrm{fc}}\right)}-1}\left[e^{\beta\left(\mathrm{S}_{\mathrm{r}}-\mathrm{S}_{\mathrm{fi}}\right)}-1\right] \text { for } S_{f c}<S_{r} \leq 1
$$

where, $\beta$ is a coefficient used to fit the equation (8) permeability function described by the equation (7). This parameter depends on type of soil and can be related to $b$ $(\beta=2 b+4)$.

During the periods between rainfall events, the decay of soil degree of saturation was described from de initial values of $S_{r}$ as proposed by Rodríguez-Iturbe et al. [12]. These values depend on the previous history of the complete process.

\section{WATER FLOW IN UNSATURATED SOIL}

For a unit length element of soil, mass conservation is mathematically expressed by

$$
\frac{\partial\left(\rho_{w} n S_{r}\right)}{\partial t}+\frac{\partial\left(\rho_{w} v_{i}\right)}{\partial x_{i}}=0
$$

where, $\rho_{w}$ is soil specific weight, $v_{i}$ is velocity of water, $t$ is time and $x_{i}$ is the direction of the coordinate system.

Assuming: (i) the water incompressible, (ii) volumetric deformation and suction as state variables, and (iii) Darcy's law is valid, it is obtained that equation that represents soil water flow is

$$
-k_{w i j} \frac{\partial^{2} h}{\partial x_{j}^{2}}+\frac{\partial \theta_{w}}{\partial t}=0
$$

where, $k_{w i j}$ is the permeability matrix that is function of degree of saturation and soil voids ratio and $\partial h / \partial x$ is the hydraulic gradient.
In order to solve the flow equation spatially, the Finite Element Method (FEM) was used, and for the temporary solution the Finite Difference Method (FDM) was used as well.

As the solution of the flow problem is expressed on terms of pore pressure or hydraulic head, it is necessary to define constitutive functions that relate permeability and moisture with this variable.

To obtain the term $\beta_{w}=\partial \theta_{w} / \partial h$, that reflects facility of water inlet or outlet on an soil element due to variations on suction, it was used the function for the Soil Water Retention Curve (SWRC) proposed by Van Genuchten [19]

$$
\Theta=\left[\frac{1}{1+\left(\alpha_{V-G} h\right)^{n_{\nu-G}}}\right]^{m_{V-G}}, \quad\left(m_{V-G}=1-1 / n_{\nu-\sigma}\right)
$$

where, $h$ is the hydraulic head, $\alpha_{V-G}, m_{V-G}$, and $n_{V-G}$, are fitting parameters and $\Theta$ is the normalized water content.

The constitutive relation for permeability is based on the same equation used on the model to obtain atmosphere-soil flows, defined by

$$
k_{w}=\left\{\begin{array}{lr}
k_{s} & 0 \leq\left(u_{a}-u_{w}\right) \leq \alpha \\
k_{s} S_{r}^{c} & \alpha<\left(u_{a}-u_{w}\right)<u_{\max } \\
k_{\min } & u_{\max } \leq\left(u_{a}-u_{w}\right)<\infty
\end{array}\right.
$$

If the pore pressure is higher than a limit value $u_{\max }$, permeability reaches a value $k_{\min }$ that depends on type of soil.

\section{CASE STUDY}

The geometry of studied slope is the same as the one of the hypothetical case presented by Otálvaro \& CordãoNeto[15]. The water table was obtained through a stationary analysis, by imposing pore pressures equal to zero at the slope foot and a constant flow of $7 \cdot 10^{-7} \mathrm{~m} / \mathrm{s}$ coming from left side. The location of water table and slope geometry are presented on Figure 3.

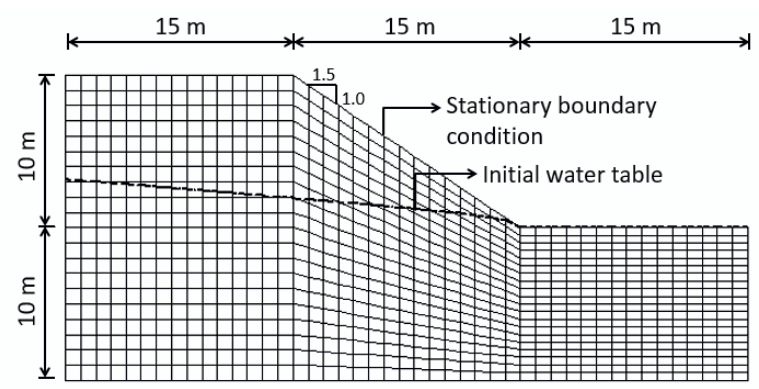

Figure 3. Geometry and initial conditions of the simulation.

Table 1 shows the parameters values used to model the soil, which is a sandy loam, the parameters of soil water retention curve and permeability curve, and the parameters of ecohydrological model. 
Table 1. Mechanical soil parameters.

\begin{tabular}{|c|c|}
\hline Parameter & Value \\
\hline Specific weight $\left[\mathrm{kN} / \mathrm{m}^{3}\right]$ & 18.1 \\
\hline Cohesion $[\mathrm{kPa}]$ & 12 \\
\hline Friction angle $\left.{ }^{\circ}\right]$ & 30 \\
\hline $\begin{array}{c}\text { Saturated hydraulic } \\
\text { conductivity }[\mathrm{m} / \mathrm{s}]\end{array}$ & $2.24 \mathrm{E}-05$ \\
\hline \begin{tabular}{c} 
Air-entry value $[\mathrm{kPa}]$ \\
\hline$\phi^{b^{*}}\left[{ }^{\circ}\right]$
\end{tabular} & 8 \\
\hline$m_{V-G}$ & 0.06 \\
\hline$n_{V-G}$ & 1.5 \\
\hline$b$ & 4.6 \\
\hline Porosity & 0.463 \\
\hline$E_{w}[\mathrm{~mm} /$ day] & 0.1 \\
\hline$S_{h}$ & 0.08 \\
\hline$S_{f c}$ & 0.35 \\
\hline *angle indicating the increase rate of shear \\
strength relative to increase matric suction.
\end{tabular}

To evaluate the influence of vegetation type on the slope stability, the values of parameters of two types of typical vegetation cover considered on simulations by Ridolfi et al. [20] were used, and are shown in Table 2.

Table 2. Parameters of the vegetation type.

\begin{tabular}{|c|c|c|}
\hline Parameter & Grass & Trees \\
\hline$\left.Z_{r} \mathrm{~mm}\right]$ & 300 & 700 \\
\hline$\Delta[\mathrm{mm}]$ & 1 & 2 \\
\hline$E_{\max }[\mathrm{mm} / \mathrm{day}]$ & 4.7 & 4.3 \\
\hline$S_{w}$ & 0.10 & 0.11 \\
\hline$S^{*}$ & 0.24 & 0.22 \\
\hline
\end{tabular}

Furthermore, simulations where made for two climate seasons, one wet and another dry, characterized by the parameters presented in Table 3. Montecarlo simulations were made for a 50-year period, with the purpose of analyzing the statistical behavior of soil moisture and slope Factor of Safety.

Table 3. Parameters of the precipitation model.

\begin{tabular}{|c|c|c|}
\hline Season & $\boldsymbol{\lambda}\left[\mathbf{d a y}^{-1}\right]$ & $\boldsymbol{\alpha}[\mathbf{m m} / \mathbf{d a y}]$ \\
\hline Wet & 0.72 & 1.15 \\
\hline Dry & 0.59 & 0.95 \\
\hline
\end{tabular}

Figure 4 shows duration curves of Factor of Safety for two covers and two pluviometric regimes. During dry season (red lines) the slope is unstable $(\mathrm{FS}<1) 3.1 \%$ of the time for grass cover, and $0.4 \%$ for trees. During wet season (blue lines) the slope remains on stable conditions for longer time for both covers, $6.6 \%$ for grass and $1.3 \%$ for trees. The arboreal cover preserves the slope on stable conditions for a longer period compared to grass, regardless the rainfall season. The results show that stability conditions ( $\mathrm{FS}>1)$ are presented even for longer period for trees cover during wet season than for grass during dry season.

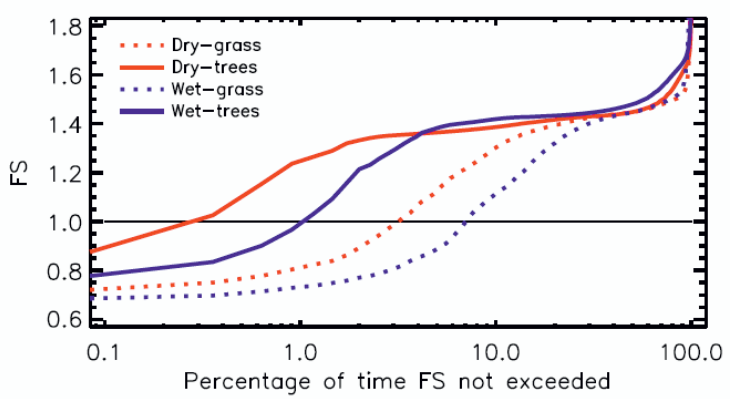

Figure 4. Percentage of non-exceedance time of FS for trees and grass during wet and dry season.

This analysis is reinforced with information of Table 4, which shows the measures of central tendency and variance of FS for all cases. The measures of central tendency change very little among climate seasons, but the dispersion changes, possibly because of the occurrence of more frequent and intense storms.

Table 4. Measures of central tendency and variance of FS for the study cases.

\begin{tabular}{|c|c|c|c|c|}
\hline Case & Mean & Mode & Median & Variance \\
\hline Dry-grass & 1.43 & 1.44 & 1.45 & 0.03 \\
\hline Dry-trees & 1.47 & 1.50 & 1.45 & 0.01 \\
\hline Wet-grass & 1.41 & 1.44 & 1.45 & 0.06 \\
\hline Wet-trees & 1.50 & 1.50 & 1.48 & 0.02 \\
\hline
\end{tabular}

The maximum evapotranspiration $\left(E_{\max }\right)$ of grass is higher than trees, indicating that if the water content is higher than the incipient wilting point $\left(S^{*}\right)$, grass evapotranspires at a higher rate than trees. However, in the model, the threshold of interception and rooting depth of trees are higher than grass, resulting on more water being retained on trees leaves, and that infiltrated water volume distributes on a larger soil volume, increasing moisture in lower proportion if porosity, initial moisture and the storm are considered the same.

On the long-term, water content tends to be higher for grass cover than for trees cover, making FS to have lower values (higher tendency to instability), due to its direct relationship with moisture. 


\section{CONCLUSIONS}

The stability of a hypothetical slope was analyzed under two vegetation covers and two pluviometric scenarios using a mechanistic model. The results showed small differences on the measures of central tendency of slope factor of safety, but there are important differences on the dispersion. The percentage of time that the slope is unstable $(\mathrm{FS}<1)$ is much larger for grass cover than for tree cover. Although this result is consistent for both rainfall scenarios, the percentage of time in which FS is less than 1 are higher during wet season than during dry season.

From our point of view, trees are able to modulate the dynamics of infiltrated water into a larger volume of soil, because their roots reach greater depths. Also, they have leaves with large surfaces that can intercept more rainfall. These two features, on the long-term, make the soil water content to remain lower for the slope covered by trees than for the slope covered by grass; regardless of that, grasses can evapotranspirate to a maximum higher rate.

Considering only the effect provided by vegetation in soil moisture, we conclude that trees make the slope more stable. Outside the scope of this work, there are other matters such as the effect of weight and the apparent soil cohesion provided by roots of each vegetation cover.

\section{ACKNOWLEDGEMENTS}

The authors thank COLCIENCIAS (Colombia), CNPq (Brazil) and CAPES (Brazil) for their financial support.

\section{REFERENCES}

1. I. Rodríguez-Iturbe, A. Porporato, L. Ridolfi, V. Isham, and D. R. Coxi, Proc. R. Soc. A Math. Phys. Eng. Sci. 455, 3789 (1999).

2. A. B. Fourie, Proc. ICE - Geotech. Eng. 119, 211 (1996).

3. G. B. Crosta, Environ. Geol. 35, 131 (1998).

4. U. Ratnayake and S. Herath, J. Mt. Sci. 2, 218 (2005).

5. E. L. Harp, M. E. Reid, J. P. McKenna, and J. A. Michael, Eng. Geol. 104, 295 (2009).

6. C. Lepore, S. a. Kamal, P. Shanahan, and R. L. Bras, Environ. Earth Sci. 66, 1667 (2011).

7. F. Wei, Y. Guolin, L. Xiaohong, and L. Liming, in 2011 Int. Conf. Consum. Electron. Commun. Networks (Ieee, 2011), pp. 3201-3205.

8. R. Giannecchini, Y. Galanti, and G. D'Amato Avanzi, Nat. Hazards Earth Syst. Sci. 12, 829 (2012).

9. J. Von Ruette, P. Lehmann, and D. Or, Water Resour. Res. n/a (2013).

10. O. A. Rueda, Modelamiento de La Humedad Del Suelo En La Región Cafetera de Colombia Bajo Diferentes Coberturas Vegetales, Master, Universidad Nacional de Colombia, 2008.

11. I. Rodríguez-Iturbe, A. Porporato, F. Laio, and L.
Ridolfi, Adv. Water Resour. 24, 695 (2001).

12. I. Rodríguez-Iturbe and A. Porporato, Ecohydrology of Water-Controlled Ecosystems (Cambridge University Press, USA, 2004).

13. P. S. Eagleson, Proc. Am. Philos. Soc. 144, 33 (2000).

14. F. Laio, A. Porporato, L. Ridolfi, and I. RodríguezIturbe, Adv. Water Resour. 24, 707 (2001).

15. I. Otálvaro and M. Cordão-Neto, in $A d v$. Unsaturated Soils, edited by B. Caicedo, C. Murillo, L. Hoyos, J. Colmenares, and I. Berdugo (Taylor \& Francis, 2013), pp. 539-543.

16. P. S. Eagleson, Water Resour. Manag. 8, 878 (1972).

17. G. S. Campbell, Soil Sci. 117, (1974).

18. C. Pimentel, A Relação Da Planta Com a Água (Editora Universidade Federal Rural do Rio de Janeiro, São Paulo, Brazil, 2001).

19. M. Van Genuchten, Soil Sci. 44, 892 (1980).

20. L. Ridolfi, P. D’Odorico, A. Porporato, and I. Rodríguez-Iturbe, J. Hydrol. 272, 264 (2003). 